\title{
A Novel Mixed Ligand Dinuclear Complex of Cobalt (II): Synthesis, Characterization and Magnetic Studies*
}

\author{
Emmanuel N. Nfor'\#, Luke L. Keenan ${ }^{2}$, Justin Nenwa ${ }^{3}$, Peter T. Ndifon ${ }^{3}$, Romanus N. Njong1, \\ Christelle N. T. Dzesse ${ }^{1}$, Offiong E. Offiong ${ }^{4}$ \\ ${ }^{1}$ Department of Chemistry, University of Buea, Buea, Cameroon \\ ${ }^{2}$ Department of Chemistry, University of Bath, Bath, UK \\ ${ }^{3}$ Department of Inorganic Chemistry, Coordination Chemistry Laboratory, University of Yaounde I, Yaoundé, \\ Cameroon \\ ${ }^{4}$ Department of Pure and Applied Chemistry, University of Calabar, Calabar, Nigeria \\ Email: nforemman@gmail.com
}

Received 14 November 2013; revised 16 December 2013; accepted 12 January 2014

Copyright (C) 2014 by authors and Scientific Research Publishing Inc.

This work is licensed under the Creative Commons Attribution International License (CC BY).

http://creativecommons.org/licenses/by/4.0/

(c) (i) Open Access

\section{Abstract}

A novel dinuclear complex $\left[\mathrm{Co}_{2}(\mathrm{atr})_{3}(\mathrm{mal})_{2}\left(\mathrm{H}_{2} \mathrm{O}\right)_{2}\right] \cdot 4 \mathrm{H}_{2} \mathrm{O}(1)$ (atr $=4$-amino-1,2,4-triazole and mal = malonic acid) containing mixed $\mathrm{N}$ - and $\mathrm{O}$-donor atoms has been prepared and structurally characterized. The structure is made up of the symmetrically 1, 2, 4-triazole bridged

$\left[\mathrm{Co}_{2}(\mathrm{atr})_{3}(\mathrm{mal})_{2}\left(\mathrm{H}_{2} \mathrm{O}\right)_{2}\right]$ moiety and four lattice water molecules. The single crystal $\mathrm{X}$-ray analysis reveals that the complex has a distorted octahedral structure. Magnetic susceptibility measurements reveals that antiferromagnetic interactions exists between the high spin Co(II) ions within the dinuclear unit.

\section{Keywords}

Dinuclear Complex; Cobalt (II) Complex; Magnetic Properties; Mixed Triazole-Malonate

\section{Introduction}

Magnetic materials constructed from the paramagnetic ions and mixed short mediators have received a great deal of attention due to their impressive structural diversities, complicated magneto-structural correlations, and

"Dedicated to Professor Offiong Efanga Offiong on the occasion of his $50^{\text {th }}$ birthday.

"Corresponding Author.

How to cite this paper: Nfor, E.N., Keenan, L.L., Nenwa, J., Ndifon, P.T., Njong, R.N., Dzesse, C.N.T. and Offiong, O.E. (2014) A Novel Mixed Ligand Dinuclear Complex of Cobalt (II): Synthesis, Characterization and Magnetic Studies. Crystal Structure Theory and Applications, 3, 22-29. http://dx.doi.org/10.4236/csta.2014.31003 
intriguing applications in high-density information storage and quantum computation [1] [2]. As compared with the differently magnetic nature of the spin carriers (magnetic anisotropy, spin-orbit coupling, and spin state transition), the mixed homo-/hetero-bridges that aggregate the spin carriers in various binding modes play more important roles in determining the sign and strength of the super-exchange couplings [3] [4]. Among the diverse choices of the mixed magnetic-active bridges (such as azido-, formato-, cyanato-, and dicyanamido-ligands), a combination of five-membered heterocyclic triazolate and three-atom nonlinear carboxylate heterobridges has recently become one of the promising candidates for the investigations of the magnetic systems with novel structures and appealing magnetic properties. Anionic triazolate and the expanded analogues can smartly hold the paramagnetic ions into various magnetic-active motifs [5] [6], such as oligonuclear clusters [7]-[9], polymeric chains with single or multiple mediators [10] [11], infinite broad ribbons [12], as well as corner-/edgesharing triangular lattices [13] [14], which have exhibited diverse magnetic phenomena with canted, frustrated, and typically antiferromagnetic couplings. More interestingly, the magnetic behavior and the relevant solid structures of these diverse magnetic samples can further be tailored by the presence of the short carboxylate mediator with conformation dependent magnetic interactions (antiferromagnetic coupling with different strength transmitted by syn, syn-/anti, anti-COO${ }^{-}$, and/or ferromagnetic interaction with syn, anti-COO${ }^{-}$) [15]. In particular, rigid polycarboxylate coligands have been found to well extend the low-dimensional magnetic structures into high-dimensional ordered ones, in which the number and position of the carboxylate group toward the phenyl backbone can essentially dominate the connectivity of the magnetic subunits [7] [16]. Furthermore in continuation with our ongoing investigations on the magnetic studies of mixed-ligand complexes [17] [18], using triazoles and carboxylates mediators, herein, 4-amino-1,2,4-triazole (atr) and malonic acid (mal) were judiciously selected as mixed mediators to self-assemble with inorganic $\mathrm{Co}^{\mathrm{II}}$ source under controllable conditions to establish and enrich the magneto-structural correlations.

\section{Experimental}

\subsection{Materials and Methods}

All reagents were purchased commercially and used without further purification. Doubly deionized water was used for conventional synthesis. Elemental analysis was performed on a Thermo Flash EA-1112 Series CHNS-O Elemental Analyzer. The IR spectra were obtained from $\mathrm{KBr}$ pellets in the range $4000-400 \mathrm{~cm}^{-1}$, using a Perkin-Elmer Spectrum $100 \mathrm{FT}$-IR spectrometer. TGA measurements were performed at the heating rate $10^{\circ} \mathrm{C} \cdot \mathrm{min}^{-1}$ in the temperature range $25-600^{\circ} \mathrm{C}$, under dry nitrogen flow of $60 \mathrm{~mL} \cdot \mathrm{min}^{-1}$ on a TGA Q500 instrument. Approximately 2 - $5 \mathrm{mg}$ of sample was placed in an open aluminum crucible. Magnetic susceptibilities were acquired on a Quantum Design SQUID MPMS-XL-7 magnetometer with polycrystalline samples, in which the phase purity of the sample was determined by PXRD experiments. The magnetic susceptibility was corrected for the contribution of the gel capsule and for the core diamagnetism (using Pascals constant).

\subsection{Synthesis of $\left[\mathrm{Co}_{2}(\mathrm{atr})_{3}(\mathrm{mal})_{2}\left(\mathrm{H}_{2} \mathrm{O}\right)_{2}\right] \cdot 4 \mathrm{H}_{2} \mathrm{O}(1)$}

A methanolic solution $\left(10 \mathrm{~cm}^{3}\right)$ of 4-amino-1,2,4-triazole $(210 \mathrm{mg} ; 2.5 \mathrm{mmol})$ was added to a warm aqueous solution $\left(20 \mathrm{~cm}^{3}\right.$ ) of cobalt (II) nitratehexahydrate (356 mg; $2.5 \mathrm{mmol}$ ). Potassium malonate (generated in situ by reacting stoichiometric amounts of malonic acid and potassium carbonate) dissolved in water (2.5 mmol; $\left.10 \mathrm{~cm}^{3}\right)$ was added to the previous warm reddish-orange solution under continuous stirring for two hours and filtered, the filtrate was allowed to slowly evaporate at room temperature and complex separated as reddish-orange crystals suitable for X-ray diffraction analysis after one week. Yield 85\%. Anal. Calcd: C, 59.92; H, 3.95; N, 19.97. Found: C, 59.57; H, 4.00; N, 19.75\%. IR (KBr, $\left.\mathrm{cm}^{-1}\right)$ : 1594.5, 1505.1, 1471.1, 1345.1, 917.2, 789.7, 669.3.

\subsection{Crystallographic Data Collection and Structure}

Suitable single crystals of Compound $\mathbf{1}$ was mounted on a Brucker SMART APEX CCD diffractometer equipped with a graphite-monochromated MoKa radiation source $(k=0.71073 \AA)$ at $150 \mathrm{~K}$. All absorption corrections were performed with SADABS program [19]. All the structures were solved by direct methods and refined with fullmatrix least-squares and expanded using Fourier techniques. The non-hydrogen atoms were refined anisotropically. Hydrogen atoms were placed in the calculate positions. All calculations were performed using SHELXTL- 
97 program [20]. The crystal parameters, data collection, and refinement result for Compound $\mathbf{1}$ is summarized in Table 1. Selected bond lengths and angles are listed in Table 2.

\section{Results and Discussion}

\subsection{Infrared Spectrum}

In the infrared spectrum, complex 1 exhibit multiple weak bands at $c a, 3466,3413$ and $3350 \mathrm{~cm}^{-1}$, corresponding to the $\mathrm{O}-\mathrm{H} / \mathrm{N}-\mathrm{H}$ stretching vibrations of hydroxyl group and exocyclic amino group of the atr ligand [21]. Instead, broad bands centered at $c a 3300 \mathrm{~cm}^{-1}$ in $\mathbf{1}$ suggest the presence of water molecule which heavily mask the weak absorptions of hydroxyl group and exocyclic amino group of atr ligand. Symmetric stretching vibrations of the malonate are observed at 1616, 1557, 1431 and $1366 \mathrm{~cm}^{-1}$ for $\mathbf{1}$. Thus, the IR spectrum of $\mathbf{1}$ is in agreement with the single-crystal X-ray diffraction.

Table 1. Crystal data and structure refinement for Compound $\mathbf{1 .}$

\begin{tabular}{|c|c|}
\hline Empirical formula & $\mathrm{C}_{12} \mathrm{H}_{28} \mathrm{Co}_{2} \mathrm{~N}_{12} \mathrm{O}_{14}$ \\
\hline FW & 682.32 \\
\hline $\mathrm{T}(\mathrm{K})$ & $150(2) \mathrm{K}$ \\
\hline Space group & $\mathrm{P} 2{ }_{1} 2_{1} 2_{1}$ \\
\hline Wavelength ( $\AA$ ) & 0.71073 \\
\hline Crystal system & Orthorhombic \\
\hline \multicolumn{2}{|l|}{ Unit cell dimensions } \\
\hline$a(\AA)$ & $9.2550(1)$ \\
\hline$b(\AA)$ & $13.9920(2)$ \\
\hline$c(\AA)$ & $19.7580(3)$ \\
\hline$\alpha(\operatorname{deg})$ & 90 \\
\hline$\beta$ (deg) & 90 \\
\hline$\gamma(\mathrm{deg})$ & 90 \\
\hline$V\left(\AA^{3}\right)$ & 2558.58(4) \\
\hline$Z$ & 4 \\
\hline $\mathrm{D}_{\mathrm{X}}\left(\mathrm{g} / \mathrm{cm}^{-3}\right)$ & 1.771 \\
\hline$\mu\left(\mathrm{mm}^{-1}\right)$ & 1.386 \\
\hline $\mathrm{F}(000)$ & 1400 \\
\hline Crystal size $\left(\mathrm{mm}^{3}\right)$ & $0.10 \times 0.08 \times 0.05$ \\
\hline$\theta$ range $(\mathrm{deg})$ & 27.485 \\
\hline Index range $(\mathrm{h}, \mathrm{k}, \mathrm{l})$ & $-12 \leq h \leq 12,-18 \leq k \leq 17,-25 \leq l \leq 25$ \\
\hline Reflection collected & 5840 \\
\hline Independent reflections $\left(\mathrm{R}_{\text {int }}\right)$ & $5153(0.0328)$ \\
\hline Absorption correction & none \\
\hline Data/restraints/parameter & $5840 / 23 / 416$ \\
\hline Goodness-of-fit on $\mathrm{F}^{2}$ & 1.043 \\
\hline Final R indices $[\mathrm{I}>2 \sigma>(\mathrm{I})]$ & $\mathrm{R} 1=0.0328, \mathrm{wR} 2=0.0702$ \\
\hline
\end{tabular}


Table 2. Selected Bond lengths $(\AA)$ and Bond angles ( ${ }^{\circ}$ ) of $\mathbf{1}$.

\begin{tabular}{|c|c|c|c|c|c|}
\hline \multicolumn{2}{|c|}{ Bond lengths } & \multicolumn{4}{|c|}{ Bond angles } \\
\hline & & N1-Co1-N10 & $91.28(9)$ & N9-Co2-N5 & $92.36(9)$ \\
\hline $\mathrm{Co}(1)-\mathrm{N}(1)$ & $2.116(2)$ & N1-Co1-N6 & $90.75(9)$ & N9-Co2-N2 & $88.46(9)$ \\
\hline $\mathrm{Co}(1)-\mathrm{N}(6)$ & 2.141(2) & N10-Co1-N6 & $90.59(9)$ & N5-Co2-N2 & $90.80(9)$ \\
\hline $\mathrm{Co}(1)-\mathrm{N}(10)$ & $2.130(2)$ & O5-Co1-O3 & 87.25(8) & N9-Co2-O2 & $175.40(9)$ \\
\hline $\mathrm{Co}(2)-\mathrm{N}(2)$ & 2.166(3) & O5-Co1-O1 & $91.11(8)$ & N5-Co2-O2 & 88.52(9) \\
\hline $\mathrm{Co}(2)-\mathrm{N}(5)$ & $2.106(2)$ & O3-Co1-O1 & $94.19(8)$ & O8-Co2-O7 & 86.81(8) \\
\hline $\mathrm{Co}(2)-\mathrm{N}(9)$ & 2.102(2) & O5-Co1-N1 & $174.53(8)$ & $\mathrm{O} 8-\mathrm{Co} 2-\mathrm{O} 2$ & $91.35(9)$ \\
\hline $\mathrm{Co}(1)-\mathrm{O}(1)$ & 2.128(2) & O3-Co1-N1 & $87.36(8)$ & O7-Co2-O2 & $96.78(8)$ \\
\hline $\mathrm{Co}(1)-\mathrm{O}(3)$ & 2.074(19) & O3-Co1-N10 & $88.05(9)$ & O7-Co2-N9 & $87.79(9)$ \\
\hline $\mathrm{Co}(1)-\mathrm{O}(5)$ & 2.062(19) & O1-Co1-N10 & $177.33(9)$ & O8-Co2-N5 & 173.25(8) \\
\hline $\mathrm{Co}(2)-\mathrm{O}(2)$ & $2.107(2)$ & O1-Co1-N6 & $87.21(9)$ & $\mathrm{O} 2-\mathrm{Co} 2-\mathrm{N} 2$ & 87.01(8) \\
\hline $\mathrm{Co}(2)-\mathrm{O}(7)$ & 2.097(2) & O5-Co1-N6 & $94.60(8)$ & O8-Co2-N2 & $95.94(8)$ \\
\hline $\mathrm{Co}(2)-\mathrm{O}(8)$ & $2.085(19)$ & N1-Co1-O1 & $90.27(9)$ & O7-Co2-N5 & $86.50(8)$ \\
\hline
\end{tabular}

Symmetry transformation used to generate equivalent atoms for 1 : 1/2 -x, -y, 1/2+x, 1/2 +x, 1/2 -y, $-\mathrm{z},-\mathrm{x}, 1 / 2+\mathrm{y}, 1 / 2-\mathrm{z}$.

\subsection{Thermal Stability and PXRD Patterns}

Thermal stability of the complex was measured from room temperature to $600^{\circ} \mathrm{C}$ (Figure 1). The TG analysis of the complex shows that the weight loss of $16.83 \%$ takes place in the temperature range $70^{\circ} \mathrm{C}-250^{\circ} \mathrm{C}$ (Figure 1), corresponding to the loss of coordinated and uncoordinated water molecules (theoretical weight loss 15.83\%). The phase purity of the bulk product of $\mathbf{1}$ was further confirmed by PXRD technique. The experimental and computersimulated PXRD patterns were in good agreement with each other, indicating the phase purity of the as-synthesized product.

\subsection{Description of the Structure}

The molecular structure of the complex $\mathbf{1}$ with atom numbering scheme is shown in Figure 2. The crystal structure refinement data for the compound is shown in Table 1, while selected bond lengths and bond angles are listed in Table 2.

The complex crystallizes in the orthorhombic system with space group $\mathrm{P} 2{ }_{1} 2_{1} 2_{1}$. The Co(II) coordination environment is a distorted octahedron with each Co atom linked to one another by means of triple $\mu-\kappa^{2} \mathrm{~N}^{1}, \mathrm{~N}^{2}$ 1,2,4-triazole bridge having C-N bond distances ranging from 2.102(2) to 2.166(3) $\AA$, one terminal malonate ligand with Co- $\mathrm{O}_{\text {malonate }}$ bond distances of 2.062(2) to 2.097(2) $\AA$. The octahedral coordination is completed by one water molecule with bond distance of $\mathrm{Co}-\mathrm{O}_{\text {water }}$ ranging from 2.107(2) to 2.128(2) $\AA$. The Co-N bond distances in the range 2.101(2) - 2.166(2) $\AA$ (Table 2) are comparable to previously reported values [22] .The Co-Co separation of 3.80546(5) $\AA$ is consistent with the value reported for a similar dinuclear Co (II) complex linked by $\boldsymbol{\mu}-\kappa^{2} \mathrm{~N}^{1}$, $\mathrm{N}^{2}$-1,2,4-triazole bridges [23].

The cobalt atom is positioned in a highly distorted octahedron where the angles subtended at the cobalt atom vary from $87.25^{\circ}$ to $177.65^{\circ}$. So the environment around the cobalt (II) atom can be described as a distorted octahedron. The distorted octahedral configuration of Co (II) can be explained by Jahn-Teller effect for the $\mathrm{d}^{7}$ configuration.

The high spin $3 \mathrm{~d}^{7}$ ion of cobalt (II) gives ${ }^{4} \mathrm{~F}_{9 / 2}$ ground term in octahedral ligand fields. Since it is a Jahn-Teller configuration, the distorted octahedron is expected. As shown in Figure 2, intermolecular hydrogen bonds exist extensively in the crystal. The intermolecular hydrogen bonds exist between the lattice water molecules (O13-H13A-014 = $2.807 \AA$ ), coordinated carboxylate and lattice water (O11-H11A-06 = $2.711 \AA$ ), coordinated water and lattice water $(\mathrm{O} 2-\mathrm{H} 2 \mathrm{~B}-\mathrm{O} 1=2.904 \AA)$ as well as the carboxylate oxygen and the 1,2, 4-triazole nitrogen atoms (N8-H8A-O4 $=2.866 \AA$ ) leading to an extended three-dimensional hydrogen-bonded structure as depicted in Figure 3.

\subsection{Magnetic Properties}

The magnetic susceptibility of $\mathbf{1}$ (Figure 4) was measured on a polycrystalline sample under an applied field of 1000 Oe. The $\chi \mathrm{mT}$ value at $300 \mathrm{~K}$ is $2.80 \mathrm{~cm}^{3} \mathrm{~mol}^{-1} \mathrm{~K}$ ( $\mu$ eff per $\left.\mathrm{Co}(\mathrm{II})=4.73 \mu \mathrm{B}\right)$, which is higher than that expected for a high-spin Co(II) ion through the spin-only formula, $c a .1 .87 \mathrm{~cm}^{3} \mathrm{~mol}^{-1} \mathrm{~K}$ with $\mathrm{g}=2.0(\mu \mathrm{eff}=3.87 \mu \mathrm{B})$ 


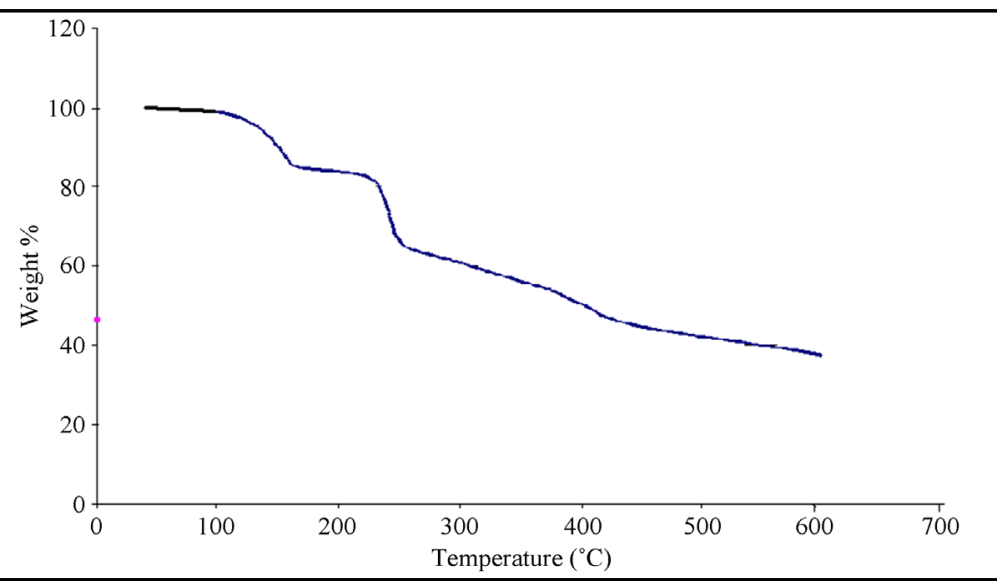

Figure 1. TGA curve of the complex 1 under $\mathrm{N}_{2}$.

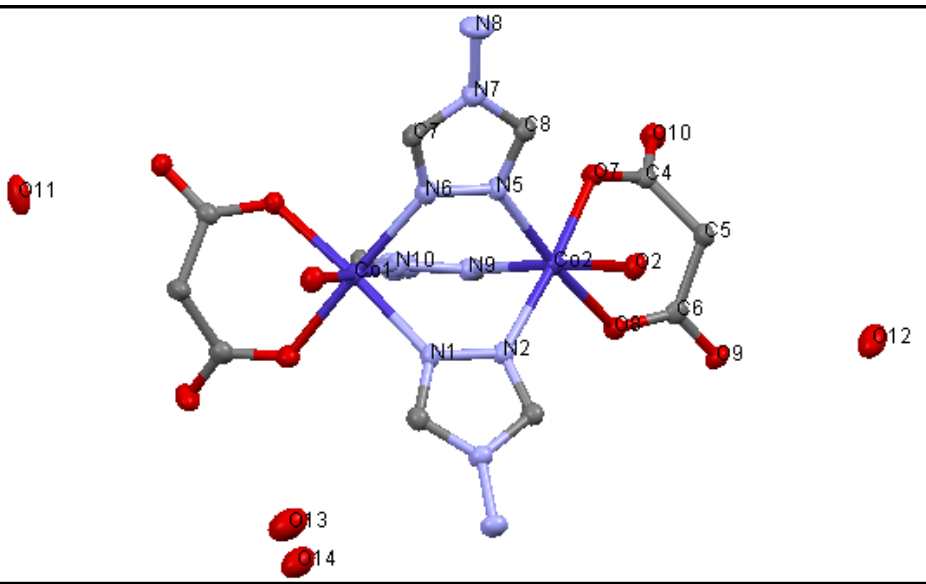

Figure 2. Perspective view of the dinuclear $\mathrm{Co}(\mathrm{II})$ complex showing the atom numbering scheme(Hydrogen atoms are omitted for clarity).

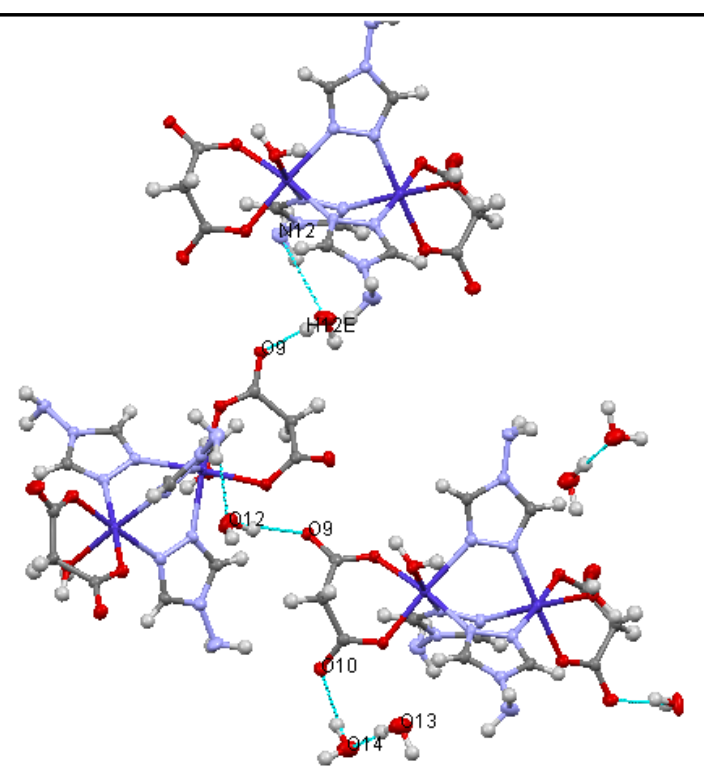

Figure 3. Intermolecular hydrogen bonds occurring in the crystal lattice of $\mathbf{1}$. 


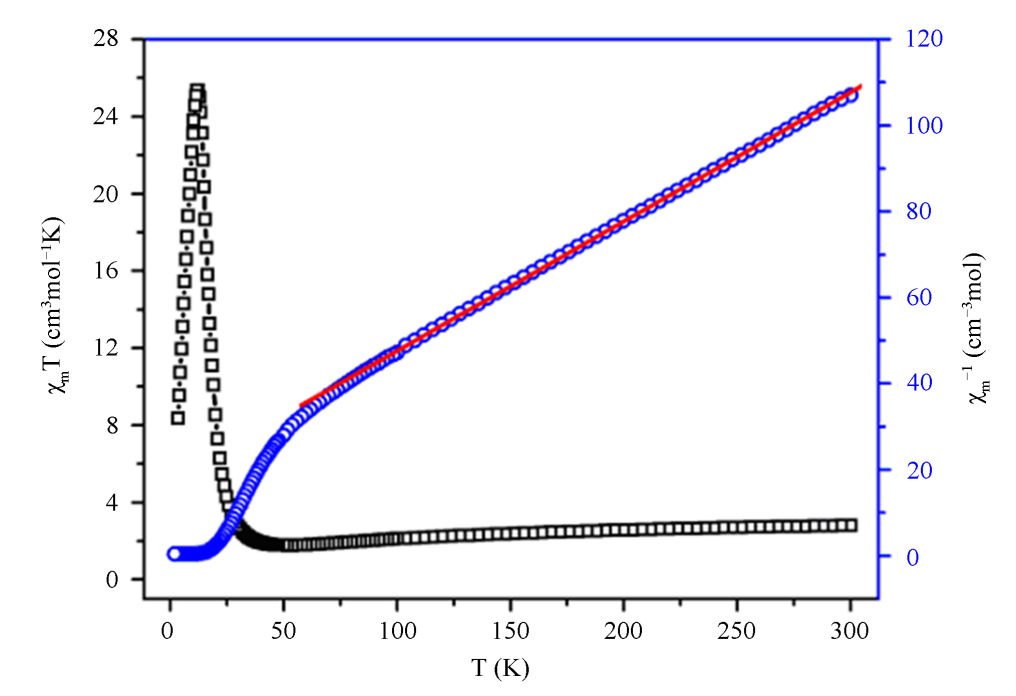

Figure 4. Temperature dependence of magnetic susceptibility $\left(\chi_{\mathrm{m}} \mathrm{T}\right)$ and inverse susceptibilities $\left(\chi_{\mathrm{m}}^{-1}\right)$ versus T plots. Red line indicates theoretical fitting for $\mathbf{1}$.

[24], thus indicating that an important orbital contribution due to the distorted octahedral $\mathrm{Co}^{\mathrm{II}}$ ion exists. The $\chi_{\mathrm{m}} \mathrm{T}$ value decreases gradually as the temperature is lowered from $300 \mathrm{~K}$ to $51 \mathrm{~K}$, reaching a minimum of 1.77 $\mathrm{cm}^{3} \mathrm{~mol}^{-1} \mathrm{~K}$ at $51 \mathrm{~K}$, which is attributed to spin-orbit coupling effects and indicates the presence of dominant antiferromagnetic interaction between two Co(II) paramagnetic centers. As the temperature is lowered the $\chi_{\mathrm{m}} \mathrm{T}$ value increases abruptly to a maximum of $25.31 \mathrm{~cm}^{3} \mathrm{~mol}^{-1} \mathrm{~K}$ at $12 \mathrm{~K}$, and then drops sharply to a minimum of 8.0 $\mathrm{cm}^{3} \mathrm{~mol}^{-1} \mathrm{~K}$ at $2 \mathrm{~K}$. This low temperature behaviour suggests a ferromagnetic phase transition. The dominant antiferromangnetic coupling mainly mediates through the $\boldsymbol{\mu}-\kappa^{2} \mathrm{~N}^{1}, \mathrm{~N}^{2}-1,2,4$-triazole pathway between two Co(II) centers in $\mathbf{1}$ at high temperature. Furthermore, the reciprocal molar magnetic susceptibility data (Figure 4) obey the Curie-Weiss law in the high temperature region of $75-300 \mathrm{~K}$ with a Curie constant of $\mathrm{C}=3.31 \mathrm{~cm}^{3} \mathrm{~mol}^{-1} \mathrm{~K}$ (close to the value of $2.8-3.4 \mathrm{~cm}^{3} \mathrm{~mol}^{-1} \mathrm{~K}$ expected for an octahedral $\mathrm{Co}(\mathrm{II})$ ion) and a Weiss constant of $\theta=$ $-53.89 \mathrm{~K}$. This large negative value of the Weiss constant supports the antiferromagnetic interaction between the Co(II) ions.

\section{Conclusion}

A novel mixed-ligand dinuclear $\mathrm{Co}(\mathrm{II})$ complex $\left[\mathrm{Co}_{2}(\mathrm{atr})_{3}(\mathrm{mal})_{2}\left(\mathrm{H}_{2} \mathrm{O}\right)_{2}\right] \cdot 4 \mathrm{H}_{2} \mathrm{O}$ has been synthesized and characterized. The complex crystallizes in an orthorhombic system and space group $\mathrm{P} 2{ }_{1} 2_{1} 2_{1}$ with the $\mathrm{Co}$ (II) ion exhibiting a distorted octahedral coordination. Magnetic susceptibility measurements of the complex reveal an antiferromagnetic interactions between the $\mathrm{Co}(\mathrm{II})$ ions within the dinuclear units.

\section{Acknowledgements}

ENN thanks the Common wealth Scholarship Commission (CSC) for Research Fellowship and Professor Andrew D. Burrows of the Department of Chemistry, University of Bath, United Kingdom for hosting the fellowship.

\section{References}

[1] Wernsdorfer, W. and Sessoli, R. (1999) Quantum Phase Interference and Parity Effects in Magnetic Molecular Cluster. Science, 284, 133-135. http://dx.doi.org/10.1126/science.284.5411.133

[2] Leuenberger, M.N. and Loss, D. (2001) Quantum Computing in Molecular Magnets. Nature, 410, 789-793. http://dx.doi.org/10.1126/science.284.5411.133

[3] Zeng, Y.-F., Hu, X., Liu, F.-C. and Bu, X.-H. (2009) Azido-Mediated Systems Showing Different Magnetic Behaviors. Chemical Society Reviews, 38, 469-480. http://dx.doi.org/10.1039/b718581m 
[4] Wang, X.-Y., Wang, Z.-M. and Gao, S. (2008) Constructing Magnetic Molecular Solids by Employing Three-Atom Ligands as Bridges. Chemical Communications, 281-284. http://dx.doi.org/10.1039/b708122g

[5] Ouellette, W., Jones, S. and Zubieta, J. (2011) Solid State Coordination Chemistry of Metal-1,2,4-Triazolates and Related Metal-4-Pyridyltetrazolates. CrystEngComm, 13, 4457-4485. http://dx.doi.org/10.1039/c0ce00919a

[6] Zhang, R.-B., Zhang, J., Li, Z.-J., Cheng, J.-K., Qin, Y.-Y. and Yao, Y.-G. (2008) Novel Copper(II) and Copper(II)Quanazolate Complexes: Structure Network, Topolgies, Photoluminescence, and Magnetic Properties. Crystal Growth \& Design, 8, 3735-3744. http://dx.doi.org/10.1021/cg800378c

[7] Yang, E.-C., Liu, Z.-Y., Shi, X.-J., Liang, Q.-Q. and Zhao, X.-J. (2010) Two 3D Triazolate-Tricarboxylate-Bridged $\mathrm{Cu}^{\mathrm{II} / 1}$ Framework by One-Pot Hydrothermal Synthesis Exhibiting Spin-Canted Antiferromagnetism and Strong Antiferromagnetic Coupling. Inorganic Chemistry, 49, 7969-7975. http://dx.doi.org/10.1021/ic100880j

[8] Liu, J.-C., Fu, D.-G., Zhuang, J.-Z., Duan, C.-Y. and You, X.-Z. (1999) Linear Trinuclear and One Dimensional Copper(ii)Complexes Containing Co-Bridging End-On Azido and Triazole Ligands: Crystal Structures and Magnetic Properties of $\left[\mathrm{Cu}_{3}(\mathrm{atrz})_{2}\left(\mathrm{~N}_{3}\right)_{6}\right]$ and $\left[\mathrm{Cu}_{3}(\mathrm{atrz})_{2}\left(\mathrm{~N}_{3}\right)\right] \mathrm{NO}_{3}$. Journal of the Chemical Society, Dalton Transactions, 23372342. http://dx.doi.org/10.1039/a900619b

[9] Zhai, Q.-G., Lu, C.-Z., Chen, S.-M., Xu, X.-J. and Yang, W.-B. (2006) Design of Novel Three-Dimensional Coordination Polymer Based on Triangular Copper 1,2,4-Triazolate Units. Crystal Growth \& Design, 6, 1393-1398. http://dx.doi.org/10.1021/cg0600142

[10] Dîrtu, M.M., Rotaru, A., Gillard, D., Linares, J., Cdjovi, E., Tinant, B. and Garcia, Y. (2009) Prediction of the Spin Transition Temperature in $\mathrm{Fe}^{\mathrm{II}}$ One-Dimensional Coordination Polymers: Anion Based Database. Inorganic Chemistry, 48, 7838-7852. http://dx.doi.org/10.1021/ic900814b

[11] Drabent, K. and Ciunik, Z. (2001) Counter Anion Dependent Symmetry of Cu ${ }^{\text {II }}$-4-Amino-1,2,4-Triazole Polymeric Chain. Chemical Communications, 1254-1255. http://dx.doi.org/10.1039/b101936h

[12] Yang, E.-C., Liu, Z.-Y., Wu, X.-Y., Chang, H., Wang, E.-C. and Zhao, X.-J. (2011) Co ${ }^{\mathrm{II}}, \mathrm{Mn}^{\mathrm{II}}$ and Cu ${ }^{\mathrm{II}}-\mathrm{Directed}$ Coordination Polymers with Mixed Tetrazolate-Dicarboxylate Heterobridges Exhibiting Spin Canted, Spin-Frustrated Antiferromagnetsm and a Slight Spin-Flop Transition. Dalton Transactions, 40, 10082-10089. http://dx.doi.org/10.1039/c1dt10958h

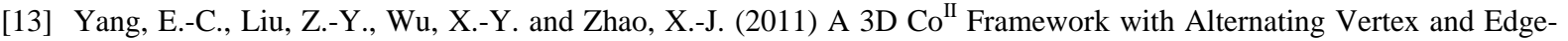
Sharing D-Ribbons Showing a Two-Step Field-Induced Magnetic Transition. Chemical Communications, 47, 86298631. http://dx.doi.org/10.1039/c1cc12796a

[14] Ouellette, W., Yu, M.H., O’Connor, C.J., Hagrman, D. and Zubieta, J. (2006) Hydrothermal Chemistry of the CopperTriazolate Systems: A Microporous Metal-Organic Framework Constructed from Magnetic $\left[\mathrm{Cu}_{3}\left(\mu_{3}-\mathrm{OH}\right)(\right.$ Triazolate $\left.)_{3}\right]^{2+}$ : Building Blocks, and Related Materials. Angewandte Chemie International Edition, 45, 3497-3500. http://dx.doi.org/10.1002/anie.200504128

[15] Rueff, J.-M., Masciocchi, N., Rabu, P., Sironi, A. and Skoulios, A. (2002) Synthesis, Structure and Magnetism of Homologous Series of Polycrystalline Cobalt Alkane Mono- and Dicarboxylate Soaps. Chemistry-A European Journal, 8, 1813-1820. http://dx.doi.org/10.1002/1521-3765(20020415)8:8<1813::AID-CHEM1813>3.0.CO;2-G

[16] Yang, E.-C., Yang, Y.-L., Liu, Z.-Y., Liu, K.-S., Wu, X.-Y. and Zhao, X.-J. (2011) Two Unique Antiferromagnetic 3D Frameworks with Unusual- $\mathrm{Cu}_{4}{ }^{\mathrm{II}}+\mathrm{Cu}_{1}{ }^{\mathrm{II}}$ Structural Motiftuned by Aromatic Polycarboxylate CO-Ligand. CrystEngComm, 13, 2667-2673. http://dx.doi.org/10.1039/c0ce00764a

[17] Nfor, E.N., Eno, E.A., Forba-Tendo, J.N., Iniama, G.E., Duke, E.O. and Offiong, O.E. (2012) Copper (II) Malonate Coordination Frameworks with Amino-1, 2, 4-Triazole: Crystal Structure and Magnetic Properties. Journal of Structural Chemistry, 53, 1118-1124. http://dx.doi.org/10.1134/S0022476612060157

[18] Nfor, E.N., Majoumo-Mbe, F., Ndifon, P.T., Duke, E.O., Mainsah, E.N., Offiong, O.E. and Eno, E.A. (2013) Synthesis, Crystal Structure, and Magnetic Properties of Bis(Aqua) [ $\mu$-(Terepthalato-kO,KO$\left.\left.{ }^{1}\right)\right]$ Copper(II) Monohydrate $\left[\mathrm{Cu}\left(\mathrm{C}_{8} \mathrm{O}_{4}\right)\right.$ $\left.\left(\mathrm{OH}_{2}\right)_{2}\right] \cdot \mathrm{H}_{2} \mathrm{O}$. Journal of Solid State Chemistry, 201,133-137. http://dx.doi.org/10.1016/j.jssc.2013.02.020

[19] Sheldrick, G.M. (1997) SADABS, Program for Scaling and Correction of Area Detector Data, University of Göttingen, Göttingen, Germany.

[20] Sheldrick, G.M. (1997) SHELXTL-97 Program for X-Ray Crystal Structure Solution, Göttingen University, Göttingen, Germany.

[21] Nakamoto, K. (1986) Infrared and Raman Spectra of Inorganic and Coordination Compounds, Wiley, New York.

[22] Vos, G., Haasnoot, J.G. , Verschoor, G. C. and Reedijk, J. (1985) Transition metal (II) Thiocyanate Coordination Compounds Containing 4-Ally-1,2,4-Triazole, Structure and Magnetic Properties. Inorganica Chimica Acta, 102, 187-189. http://dx.doi.org/10.1016/S0020-1693(00)86758-4

[23] Engelfriet, D.W., Verschoor, G.C. and Den Brinker, W. (1980) 1,2,4-Triazole Complexes IX. The Structure of Tris- $\mu$ (4-Phenyl-1,2,4-Triazole- $\mathrm{N}^{1}, \mathrm{~N}^{2}$ )Bis[Bis(Isothiocyanate) (4-Phenyl-1, 2, 4-Triazole- $\mathrm{N}^{1}$ ) Cobalt (II)] Hydrate. Acta 
Crystallographica Section B, 36, 1554-1560. http://dx.doi.org/10.1107/S0567740880006577

[24] Carlin, R.L. (1986) Magnetochemistry. Springer, Berlin, Heidelerg. http://dx.doi.org/10.1007/978-3-642-70733-9

\section{Appendix A. Supplementary Material}

CCDC 940976 contains the supplementary crystallographic data for $\mathbf{1}$. This data can be obtained free of charge via http://www.ccdc.cam.ac.uk/conts/retrieving.html, or from Cambridge Crystallographic Data Centre, 12 Union Road, Cambridge CB2 1EZ, UK (fax (44) 1223-336-033; e-mail: deposit@ccdc.cam.ac.uk). 